\title{
Lung gas exchange in simple pneumoconiosis of coal workers
}

\author{
J. E. COTES and G. B. FIELD \\ MRC Pneumoconiosis Unit, Llandough Hospital, Penarth, Glam.
}

\begin{abstract}
Cotes, J. E., and Field, G. B. (1972). Brit. J. industr. Med., 29, 268-273. Lung gas exchange in simple pneumoconiosis of coal workers. Indices of lung function and gas exchange, including some based on measurement of the arterial blood gases and physiological response to exercise, were obtained in 19 coal workers with simple pneumoconiosis of the pinhead or micronodular type, of whom 11 also had bronchitis. p-Type pneumoconiosis differed from the m-type in being associated with a smaller transfer factor, larger physiological deadspace relative to tidal volume $(\mathrm{Vd} / \mathrm{Vt})$, and increased ventilation during submaximal exercise. $\mathrm{Vd} / \mathrm{Vt}$ was also raised in patients with bronchitis. The venous admixture effect (including physiological shunt) was within normal limits. Breathing oxygen increased Vd/Vt in patients with bronchitis but not with p-type pneumoconiosis. The findings are evidence for p-type pneumoconiosis being associated with abnormal function of the lung parenchyma; the changes are consistent with cystic lung.
\end{abstract}

Mild hypoxaemia at rest and on exercise is observed in coal workers with simple pneumoconiosis compared with control subjects (Brasseur, 1963). Early evidence that this may be more marked in pneumoconiosis of the pinhead type as compared with the micronodular type (Worth, Muysers, and Siehoff, 1963) has recently been confirmed for maximal exercise by Frans (1970). There is now good evidence that this difference is associated with lower values for the transfer factor (diffusing capacity) for carbon monoxide measured by the single breath method (Billiet and Ulburghs, 1966; Lyons, Clarke, Hall, and Cotes, 1967; Cotes, Deivanayagam, Field, and Billiet, 1972). These changes constitute two components of the syndrome of defective gas transfer (Scadding, 1966), of which the third is hyperventilation during exercise. The present study was planned to investigate this third component and also to look for other evidence of defective lung gas exchange in these patients.

\section{Subjects and methods}

The subjects were 19 coal workers with simple pneumo- coniosis of whom some also had category A progressive massive fibrosis. Their characteristics are listed in Table $1^{1}$. The subjects had previously experienced all of the procedures apart from arterial cannulation; they were contacted at their homes by a third party who explained the procedures and invited participation. An approach was also made to their general practitioners. Subjects who accepted were subsequently free to withdraw if they wished to do so. Loss of earnings was paid in full.

The chest radiographs at the time of assessment were read by three readers (W.P.A., W.G.C. and J.E.C.) for category of simple pneumoconiosis $(1,2$ or 3 on the ILO classification (International Labour Office, 1959)) also for the type of opacity which was read under four headings, namely $\mathrm{p}$, mixed but predominantly $\mathrm{p}$, mixed but predominantly $\mathrm{m}$, and $\mathrm{m}$. Subjects whose radiographs showed a reticular pattern were excluded. All the subjects had normal systemic blood pressure and were free from symptoms referable to the cardiovascular system. Bronchitis was diagnosed on the basis of answers to the MRC questionnaire on respiratory symptoms (Medical

${ }^{1}$ Data for individual subjects, of which the means are given in this and subsequent tables, may be obtained from the authors. 
TABLE 1

Details of Subjects: Subdivided by Type of PNeumoconiosis AND Whether or Not they had Bronchitis (i.e., Cough and Phlegm for Three Months in the Year)

\begin{tabular}{|c|c|c|c|c|}
\hline & \multicolumn{4}{|c|}{ Category of pneumoconiosis } \\
\hline & $\begin{array}{c}\text { Pred } \\
\text { No bronchitis }\end{array}$ & $\begin{array}{l}\text { nantly } p \\
\text { Bronchitis }\end{array}$ & $\begin{array}{c}\text { Predor } \\
\text { No bronchitis }\end{array}$ & ntly $\underset{\text { Bronchitis }}{m}$ \\
\hline $\begin{array}{l}\text { No. of smokers/non-smokers } \\
\text { Age }(\mathrm{yr}) \text { mean (range) } \\
\text { Height }(\mathrm{m}) \text { mean (range) } \\
\text { Weight }(\mathrm{kg}) \\
\text { mean (range) }\end{array}$ & $\begin{array}{cl}3 / 2 \\
46 \cdot 2 \quad(39-51) \\
1.65 & (1 \cdot 54-1 \cdot 75) \\
66 \cdot 4 \quad(56-87 \cdot 5)\end{array}$ & $\begin{array}{cl} & 2 / 2 \\
51 \cdot 8 & (42-63) \\
1 \cdot 73 & (1 \cdot 68-1 \cdot 78) \\
69 \cdot 8 \quad(56-77)\end{array}$ & $\begin{array}{cl} & 2 / 1 \\
51 \cdot 0 & (49-55) \\
1 \cdot 71 & (1 \cdot 70-1 \cdot 72) \\
78 \cdot 2 & (68-86)\end{array}$ & $\begin{array}{cl}3 / 4 \\
52 \cdot 0 \quad(45-64) \\
1 \cdot 75(1 \cdot 62-1 \cdot 81) \\
71 \cdot 1 \quad(54-88)\end{array}$ \\
\hline
\end{tabular}

Research Council, 1966), in particular question 6 which takes the form 'Do you bring up phlegm like this (i.e., first thing in the morning, during the day or at night) on most days (or nights) for a smuch as three months each year?' Measurements of lung function, including the forced expiratory volume and vital capacity, the single breath transfer factor for carbon monoxide, and its subdivisions (the diffusing capacity of the alveolar membrane and the volume of blood in the lung capillaries) were made on the day preceding the exercise study using standard methods (Cotes, 1968).

The physiological results were analysed with respect to type of simple pneumoconiosis, i.e., predominantly ptype or predominantly m-type; an allowance was made for the possible effects of variation between subjects in age, height, smoking habits, and presence or absence of bronchitis.

In the ward on the morning of the study a $4-\mathrm{cm}$ Teflon catheter, internal diameter $1.0 \mathrm{~mm}$ (Longdwel, Beckton Dickinson), was inserted percutaneously into the brachial artery. In addition, in some subjects a miniature catheter, internal diameter $0.5 \mathrm{~mm}$ (Bradley, 1964), was inserted via a venous catheter into the left median cubital vein and floated into the main pulmonary artery so that its tip lay about $6 \mathrm{~cm}$ above the pulmonary valve. Details of this procedure are available elsewhere (Field and Cotes, 1970).

Arterial blood samples were taken anaerobically into 10-ml ungreased glass syringes previously lubricated with heparin solution. Analysis for $\mathrm{PO}_{2}$ was made within 10 minutes using an EIL electrode system calibrated before and after each measurement with gas mixtures analysed by the Scholander technique. A predetermined correction factor of 1.075 was applied to readings of $\mathrm{PO}_{2}$ to allow for the blood-gas difference of the oxygen electrode.

Ventilation was measured using a dry gas meter (Parkinson and Cowan) fitted with an optical integrator and counter which was read and reset each minute (Reynolds, 1968); the gas meter was positioned on the inspiratory side of the valve box and mouthpiece and was supplied with compressed air through a low-pressure demand system. On inspiration the suction required for a flow rate of $100 \mathrm{l} / \mathrm{min}$ was $1.5 \mathrm{cmH}_{2} \mathrm{O}$ and on expiration at the same flow rate the back pressure was $3 \cdot 7 \mathrm{cmH}_{2} \mathrm{O}$. The mean oral pressure at a ventilation minute volume of $50 \mathrm{l} / \mathrm{min}$ was $0.4 \mathrm{cmH}_{2} \mathrm{O}$. Expiration was to atmosphere via a gas-mixing chamber (capacity 4 litres) and an exit pipe from which a sample of mixed expired gas was drawn continuously through the gas analysers; these were, for oxygen, a Servomex OA137 paramagnetic analyser and, for carbon dioxide, a Hartmann and Braun URAS3 infrared analyser. The accuracy of analysis was that expected using these methods (Cotes and Woolmer, 1962). Respiratory frequency was recorded on one channel of a Mingograf recorder using a thermistor mounted in the valve box; another channel of the recorder was used to monitor the cardiac frequency from electrodes applied to the chest.

Measurements were made with the subjects seated upright on a bicycle ergometer. Exercise was performed by all subjects at both 40 watts and at a higher work level; this varied between subjects but was, on average, 78 watts and 88 watts for the $\mathrm{p}$ and $\mathrm{m}$ subjects respectively. Air was breathed at rest and at all levels of exercise, oxygen at rest and at the highest level of exercise. The order of administration of air and oxygen was random.

At least 10 minutes was allowed between each period of measurement. In addition, when breathing oxygen the mixed expired nitrogen concentration was required to be less than $1 \%$ before resting measurements were made or exercise was begun. Following oxygen administration the next stage of the study was not begun until the mixed expired oxygen concentration had fallen to its initial value.

Measurements of ventilation and blood gas tension at rest were made between the eighth and twelfth minutes after connecting the subject to the mouthpiece. During exercise, which was of 6 minutes duration, samples of blood for estimation of the arterial blood gas tensions were taken during the fifth minute. For the other indices the means of the fourth and sixth minutes are reported.

From these data indices of uneven lung function were calculated, including the physiological deadspace expressed as a percentage of tidal volume $(V \mathrm{~d} / V \mathrm{t})$, the venous admixture effect breathing air expressed as a percentage of cardiac output ( $\dot{Q} \mathrm{va} / \dot{Q} \mathrm{t})$, and the pulmonary blood shunt breathing oxygen $(\dot{Q} s / Q \mathrm{t})$. In the calculations the tension of carbon dioxide in alveolar gas was assumed to be the same as that measured in arterial blood. The tension difference for oxygen between alveolar gas (calculated from the alveolar air equation) and blood leaving the alveolar capillaries was assumed to be 1 torr. Allowance was made for the deadspace of the valve box. Oxygen uptake was calculated at rest and for each minute of exercise breathing air; from these and 
related data graphs were constructed for ventilation minute volume and cardiac frequency on oxygen uptake and of ventilation minute volume on tidal volume. Best fitting lines were drawn by eye and used to obtain by interpolation the ventilation minute volume and cardiac frequency at an oxygen uptake of $1.01 . \mathrm{min}^{-1}\left(\dot{V} \mathrm{E}_{1.0}\right.$ and $\mathrm{Cf}_{1.0}$ respectively) and tidal volume at a ventilation minute volume of $301 . \mathrm{min}^{-1}(V \mathrm{t}, 30)$.

\section{Results}

The subjects were found to have normal vital capacities; the mean levels for other indices were also within the normal range (Table 2). For subjects with predominantly m-type simple pneumoconiosis the residual volume both in absolute units and as a percentage of total lung capacity was greater than in the p-type cases $(P<0.05)$; however, the difference was mainly due to small variations in age and size between the subjects and disappeared when these were allowed for. The transfer factor in the men with p-type simple pneumoconiosis was, on average, $25.4 \mathrm{ml}$. min $^{-1}$ torr $^{-1}$; this was significantly less than with m-type pneumoconiosis (mean difference $5.2 \mathrm{ml} . \mathrm{min}^{-1}$ torr $^{-1}, \mathbf{P}<0.05$ ). Similar but nonsignificant differences were observed for the transfer coefficient (transfer factor per unit lung volume 4.3 and $5.0 \mathrm{~min}^{-1}$ torr $^{-1}$ respectively) and, to a lesser degree, for the subdivisions of the transfer factor, the diffusing capacity of the alveolar membrane ( $D \mathrm{~m} 54$ and $60 \mathrm{ml} . \mathrm{min}^{-1}$ torr $^{-1}$ respectively) and the volume of blood in lung capillaries ( $V$ c 56 and $64 \mathrm{ml}$ respectively). The difference in transfer factor was not explicable in terms of minor differences in age, height or smoking habits between the groups.

The data for exercise ventilation and cardiac frequency are summarized in Table 3. This shows that while the cardiac frequency for both groups of men was at or below the normally expected level, the exercise ventilation $\left(\dot{V}_{\mathrm{E}, 1.0}\right)$ was increased in the subjects with predominantly p-type simple pneumoconiosis. Analysis of variance showed that compared with m-type simple pneumoconiosis p-type pneumoconiosis increased the exercise ventilation at the oxygen uptake of $1.01 . \mathrm{min}^{-1}$ by $6.7 \pm 2.41 . \mathrm{min}^{-1}$ $(\mathbf{P}<0.02)$. There was no comparable difference attributable to bronchitis and no difference attributable to p-type pneumoconiosis at rest. On this account the regression coefficient of ventilation minute volume on oxygen uptake calculated from the data for rest and exercise at 40 watts breathing air was increased in the p-type cases $(P<0.05)$. The relationship of exercise tidal volume to minute volume $(V \mathrm{t}, 30)$ was not materially different between the subject groups.

The blood gas data and related indices are summarized in Table 4; this shows that the tensions of oxygen and carbon dioxide in arterial blood are, on average, at the normal level at rest and both levels of exercise. The venous admixture effect and alveolar to arterial tension difference for oxygen are also normal. The flow of blood through the physiological shunt is of comparable magnitude at rest and on exercise; on this account the ratio index $Q^{\mathrm{s}} / \phi_{\mathrm{t}}$ is reduced on exercise. For none of these indices is there a significant difference between the several types of simple pneumoconiosis. By contrast, the physiological deadspace as a percentage of tidal volume is above average compared with normal subjects of this age and, while the level diminishes during exercise, the extent of the reduction is less

TABLE 2

Mean Values for Indices of Lung Function in the Four Subject Groups together with Average Values for Healthy Men of the Same Mean Age and Height (for Sources See Cotes, 1968)

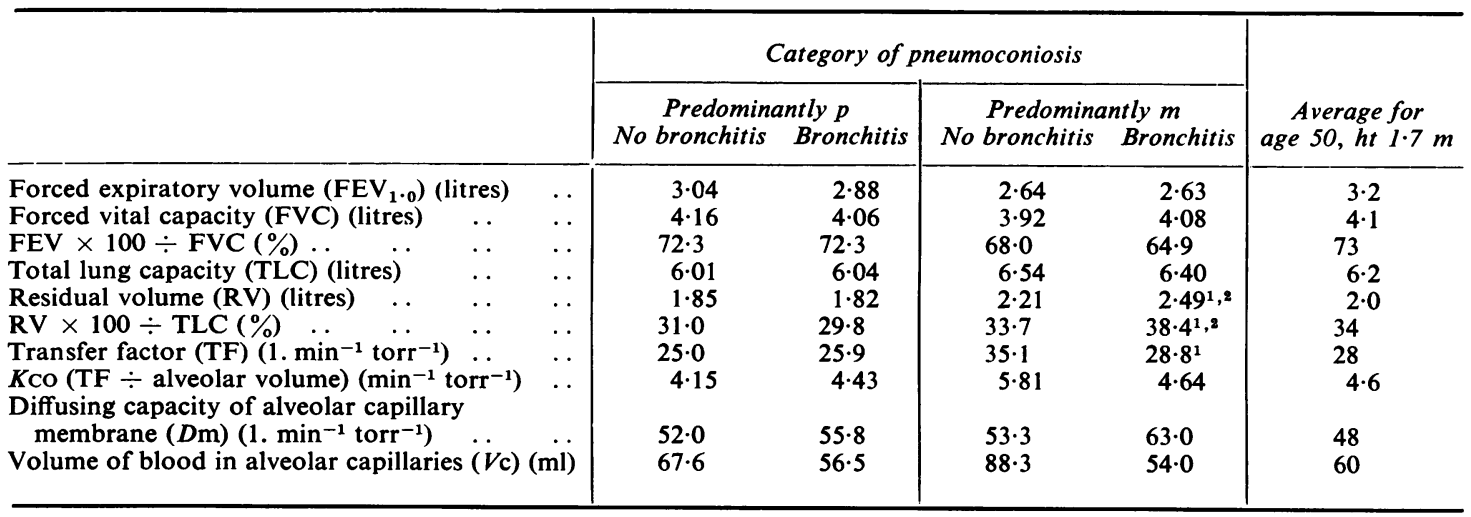

${ }^{1}$ Significant difference between $p$-type and m-type pneumoconiosis $(P<0.05)$.

${ }^{2}$ Difference no longer significant after standardizing for age and height. 
TABLE 3

Mean Values for Indices Describing the Physiological Response to Submaximal Exercise in the Four Subject Groups together with Average Values for Healthy Men (Cotes, 1968)

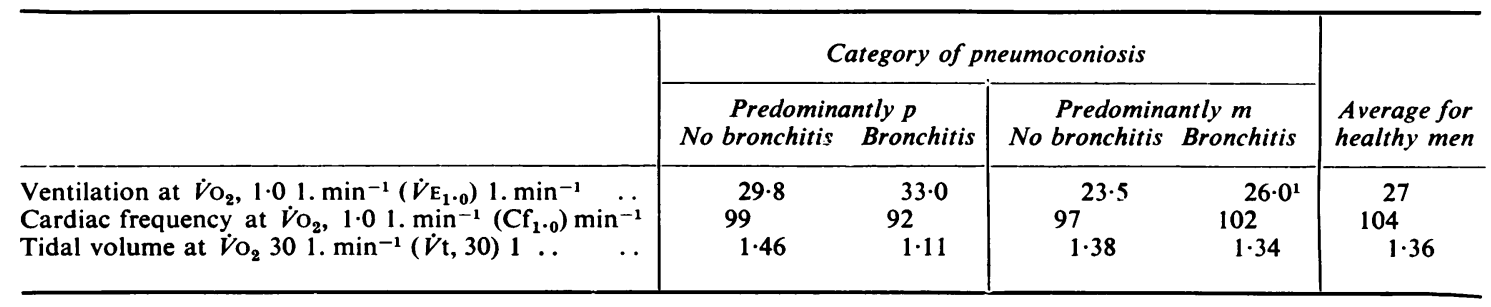

$\dot{\mathrm{O}}_{2}$ is consumption of oxygen.

'Significant difference between p-type and m-type pneumoconiosis.

than expected. Analysis of variance shows that both at rest and on exercise higher values for $V \mathrm{~d} / V \mathrm{t}$ are observed for subjects with bronchitis compared with those without and for subjects with the p-type compared with the m-type simple pneumoconiosis $(P<0.05)$. The changes associated with these two conditions are of similar magnitude, bronchitis alone increasing $V \mathrm{~d} / V \mathrm{t}$ by $10.9 \pm 3.6 \%$ and p-type pneumoconiosis by $8.0 \pm 3.6 \%$. When both conditions occur together their effect is additive and there is no evidence for interaction between them. The increase in deadspace associated with bronchitis but not that associated with p-type pneumoconiosis is augmented by breathing oxygen (mean changes for bronchitis $+4.7 \%$, range 0 to $11 \%$, and for ptype simple pneumoconiosis $-0.4 \%$, range +10 to $-9 \%$ ).

Measurements of exercise cardiac output and pulmonary arterial pressure were made on eight subjects, of whom four gave a history of persistent cough and phlegm, while four had no bronchitis. Six of the subjects had m-type and two predominantly p-type simple pneumoconiosis. In all subjects the pulmonary arterial mean pressure was normal at rest. In subjects with simple pneumoconiosis but no bronchitis the increase in pressure relative to the increase in cardiac output during exercise was similar to that reported by others for normal subjects. In subjects who had bronchitis as well as pneumoconiosis the pulmonary arterial mean pressure relative to cardiac output was consistently higher than in subjects without bronchitis; in addition, their pressure/flow curves were steeper and during moderate exercise did not show the normal tendency to level off to a constant pressure over a range of cardiac outputs which was a feature of the curves of

\section{TABLE 4}

Mean Values for Arterial Blood Gas Tensions and Indices of Ventilation Perfusion Inequality in the Four Subject Groups together with Average Values for Healthy Men (Cotes, 1968)

\begin{tabular}{|c|c|c|c|c|c|c|c|c|c|c|}
\hline & & & & \multicolumn{2}{|c|}{ Rest } & \multicolumn{2}{|c|}{40 Watts } & \multicolumn{2}{|c|}{$\begin{array}{c}\text { Highest work } \\
\text { level }\end{array}$} & \multirow{2}{*}{$\begin{array}{l}\text { Average for } \\
\text { healthy men }\end{array}$} \\
\hline & & & & $p$ & $m$ & $p$ & $m$ & $p$ & $m$ & \\
\hline \multirow[t]{3}{*}{ Arterial blood $\mathrm{O}_{2}$ tension $\left(\mathrm{PaO}_{2}\right)$ (torr) } & . & . & š B & $94 \cdot 3$ & $91 \cdot 8$ & $92 \cdot 9$ & $87 \cdot 7$ & $87 \cdot 9$ & $89 \cdot 4$ & 93 \\
\hline & , & 1 & $\mathbf{B}$ & 37.8 & $\begin{array}{l}90 \cdot 3 \\
40 \cdot 7\end{array}$ & $\begin{array}{l}88 \cdot 0 \\
36 \cdot 8\end{array}$ & $\begin{array}{l}94 \cdot 2 \\
44 \cdot 0\end{array}$ & $\begin{array}{l}81 \cdot 3 \\
38 \cdot 4\end{array}$ & $\begin{array}{l}93 \cdot 0 \\
38 \cdot 7\end{array}$ & \\
\hline & & & č B & $37 \cdot 3$ & $37 \cdot 4$ & $42 \cdot 5$ & $41 \cdot 4$ & $40 \cdot 3$ & $41 \cdot 6$ & 40 \\
\hline \multicolumn{3}{|c|}{ Physiological deadspace relative to tidal volume $(V \mathrm{~d} \times$} & క $\mathbf{B}$ & $39 \cdot 6$ & $29 \cdot 0$ & $31 \cdot 8$ & $23 \cdot 0$ & $31 \cdot 6$ & $20 \cdot 7$ & $<30 \%$ rest \\
\hline 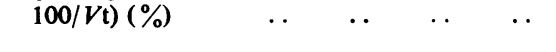 & & .. & č B & $50 \cdot 0$ & $42 \cdot 9$ & $40 \cdot 8$ & $34 \cdot 7$ & $39 \cdot 8$ & $33 \cdot 9^{2}$ & $\begin{array}{l}<20 \% \\
\text { exercise }\end{array}$ \\
\hline Venous admixture effect $(Q \mathrm{va} \times 100 / Q \mathrm{t})(\%)$ & . & . & š B & $4 \cdot 8$ & $4 \cdot 8$ & $3 \cdot 2$ & $3 \cdot 7$ & $5 \cdot 2$ & 4.4 & \\
\hline \multirow{2}{*}{ Physiological shunt $(Q \mathrm{~s} \times 100 / Q \mathrm{t})(\%)$} & $\ldots$ & $\ldots$ & $\begin{array}{l}\text { C B } \\
\text { S B B }\end{array}$ & $\begin{array}{l}5.6 \\
2.9\end{array}$ & $\begin{array}{l}4 \cdot 1 \\
3 \cdot 1\end{array}$ & - & $2 \cdot 2$ & $\begin{array}{l}3 \cdot 4 \\
1.4\end{array}$ & $\begin{array}{l}2 \cdot 6 \\
1 \cdot 5\end{array}$ & $<5 \%$ \\
\hline & & & č B & $5 \cdot 1$ & $2 \cdot 7$ & - & - & $1 \cdot 7$ & $1 \cdot 1^{3}$ & $<2 \%$ \\
\hline
\end{tabular}

${ }^{1}$ For $\mathrm{p}$ and $\mathrm{m}$ subjects these were on average 78 and $88 \mathrm{~W}$, oxygen uptake respectively 1.50 and $1.621 . \mathrm{min}^{-1}$.

2Significant differences with respect to work levels, pneumoconiosis, and bronchitis.

${ }^{3}$ Significant difference with respect to work levels

$\checkmark \mathbf{B}=$ without bronchitis

$\check{\mathbf{c}} \mathbf{B}=$ with bronchitis 
the non-bronchitic subjects. Further details of these results are given elsewhere (Field and Cotes, 1970).

\section{Discussion}

The present subjects were in good health at the time of study and while a high proportion had simple chronic bronchitis (Medical Research Council, 1965), few had recurrent episodes of chest illness. The ventilatory capacity, lung volumes, and transfer factor did not differ between those with and without cough and phlegm. This is consistent with the findings of other studies on clinically mild bronchitis in which abnormality was detected only by additional tests (Macklem, Thurlbeck, and Fraser, 1971). In the present instance bronchitis was associated with both an increase in physiological deadspace $(V \mathrm{~d} / V \mathrm{t}$, Table 4) and pulmonary hypertension on exercise. For the subjects without bronchitis, the normal values we observed for pulmonary arterial pressure in relation to cardiac output are consistent with other more extensive studies on simple pneumoconiosis of coal workers (Kremer, 1970). The lower transfer factor in simple pneumoconiosis of the pinhead than of the micronodular type confirms our earlier observation and is fully consistent with the other studies cited. The arterial oxygen tension and alveolar-arterial oxygen tension difference at rest and on exercise are within normal limits, which is evidence that the reduction in transfer factor is insufficient to exert any material influence upon gas exchange. The venous admixture effect is also normal. However, for subjects with p-type but not with m-type pneumoconiosis the arterial-oxygen tension difference at the highest work level is negatively correlated with the transfer factor $(r=-0 \cdot 9$, $P<0.01)$. This suggests that these subjects may become susceptible to hypoxaemia in the event of any further reduction in TF. More marked changes at the present time might have been expected in view of the abnormalities observed by the Belgian workers. However, whereas in the earlier series (Brasseur, 1963) hypoxaemia was observed in association with simple pneumoconiosis both at rest and throughout exercise, in the latter series (Frans, 1970) hypoxaemia was observed only at a work rate of 120 watts; this is higher than the rates attained by the present subjects (on average 83 watts, oxygen uptake 1.56 1. min $^{-1}$ ), so our findings and those of Frans are not inconsistent. The normal values for $\mathbf{P C O}_{2}$ at rest and their constancy during exercise are evidence that the alveolar ventilation was appropriate for the level of oxygen uptake. But the physiological deadspace as a percentage of tidal volume was, on average, higher than expected for normal subjects both at rest (Raine and Bishop, 1963) and on exercise (Asmussen and Nielsen, 1956).

An increase in physiological deadspace is due to some regions of the lung having a disproportionately large ventilation relative to perfusion. In patients with bronchitis the uneven ventilation is due to narrowing of airways and is partly compensated for by local pulmonary vasoconstriction, which has the effect of reducing the ventilation-perfusion inequality. On this account the pulmonary arterial pressure is increased, particularly during exercise (Field and Cotes, 1970), and the administration of oxygen, by relaxing the constricted pulmonary arteries, increases the physiological deadspace (Lee and Read, 1967). In patients with m-type pneumoconiosis without bronchitis the physiological deadspace is within normal limits but in the p-type pneumoconiosis the physiological deadspace is increased. The change is of the same order as that associated with bronchitis but whereas in bronchitis the pulmonary arterial pressure is increased, in simple pneumoconiosis without bronchitis the pulmonary arterial pressure is usually within normal limits (Kremer, 1970; Field and Cotes, 1970). Thus the mechanism of the increase in deadspace is likely to differ as between p-type simple pneumoconiosis and bronchitis, except when the two conditions coexist. The enlarged deadspace in the p-type cases may alternatively be due to expansion of airways which, in the form of focal emphysema, has for long been associated with simple pneumoconiosis (Gough, James, and Wentworth, 1949) and, as recent evidence suggests, occurs in the pinhead rather than the micronodular type of the condition (Ryder, Lyons, Campbell, and Gough, 1970; Rossiter, 1970).

The presence of expanded respiratory bronchioles (centrilobular emphysema) would add a serial deadspace between the terminal bronchioles and the alveoli. In these circumstances the maintenance of a normal alveolar ventilation would necessitate an increase in minute ventilation. This pattern of function is consistent with our findings of a normal tension for carbon dioxide in arterial blood in pinhead pneumoconiosis but an increase in minute ventilation compared with micronodular cases.

The enlargement of airspaces might also disturb the balance of ventilation to perfusion in the primary lobules served by the affected airways. However, whereas with narrowing of airways, disturbance to ventilation perfusion ratios would be inevitable unless corrected by vasoconstriction, with enlargement of airspaces the disturbance might be minimal in the early stages. That this is so in the present instance is suggested by absence of evidence for compensatory vasoconstriction including no pulmonary hypertension on exercise and no increase in physiological deadspace during oxygen breathing.

The reduction in transfer factor in pinhead pneumoconiosis, unlike the increases in deadspace and exercise ventilation, cannot be explained solely on the basis of enlargement of airways. The reduction 
suggests a partial loss of function of gas exchanging tissue of the lung, for example, those alveoli which open off the affected respiratory bronchioles. The impairment might take the form of (1) an increase in the path length for diffusion in the gas phase due to absence of ventilation, but for this there is no evidence, (2) destruction of alveoli or compression of interalveolar capillaries secondary to enlargement of airspaces, and (3) thickening of interalveolar septa by fibrous tissue and its precursors. The histological evidence on which to decide between these alternatives is so far incomplete but both the latter processes may contribute (Lyons, 1970 personal communication; Wagner, 1971).

Thus the present findings of an increase in physiological deadspace leading to an increase in exercise ventilation in p-type simple pneumoconiosis provide further evidence in this condition for impaired function of the lung parenchyma. The changes, by increasing the ventilatory requirement for exercise without a comparable increase in ventilatory capacity, may be expected to lead to patients with p-type pneumoconiosis experiencing greater breathlessness on exertion than those with m-type opacities of comparable profusion; the magnitude of the subjective effect has still to be established. Its influence upon exercise capacity may be assessed very approximately in terms of the highest work levels at which measurements were made in the two groups of subjects ( $78 \mathrm{~W}, \mathrm{O}_{2}$ uptake $1.501 . \mathrm{min}^{-1}$ and $88 \mathrm{~W}$, $\mathrm{O}_{2}$ uptake $1.631 . \mathrm{min}^{-1}$ respectively). The physiological features of p-type pneumoconiosis are consistent with cystic lung; the exact nature and natural history of the abnormality have still to be established by longitudinal study.

We are indebted to Dr. P. D. Oldham for statistical advice, to Messrs W. P. Audsley and W. G. Clarke for reading the chest radiographs, and to the Misses $\mathbf{J}$. M. Dabbs, C. Exall and A. M. Hall for invaluable assistance. One of us (G.B.F.) was supported in part by a Joint Coal Board of New South Wales Travel Grant in Industrial Medicine.

\section{References}

Asmussen, E., and Nielsen, M. (1956). Physiological dead space and alveolar gas pressures at rest and during muscular exercise. Acta physiol. scand., 38, 1-21.

Billiet, L., and Ulburghs, M. (1966). Alveolo-capillair blok door kleinvlekkige silicose: commentaar bij 4 gevallen. Acta tuberc. pneumol. belg., 57, 151-152.

Bradley, R. D. (1964). Diagnostic right-heart catheterisation with miniature catheters in severely ill patients. Lancet, 2, 941-942.

Brasseur, L. (1963). L'exploration Fonctionnelle Pulmonaire dans la Pneumoconiose des Houilleurs. Editions Arscia, S.A., Brussels.

Cotes, J. E. (1968). Lung Function: Assessment and Application in Medicine, 2nd ed. Blackwell Scientific Publications, Oxford.

_- Deivanayagam, C. N., Field, G. B., and Billiet, L. 2 (p or $\mathrm{m}$ ) and lung function. Third International Symposium on Inhaled Particles and Vapours, London 1970.

- , and Woolmer, R. F. (1962). A comparison between twenty-seven laboratories of the results of analysis of an expired gas sample. J. Physiol. (Lond.), 163, 36P-37P.

Field, G. B., and Cotes, J. E. (1970). Lability of pulmonary pressure/flow curves during exercise in clinically mild bronchitis; evidence for a pulmonary vascular sluice in man. Clin. Sci., 38, 461-477.

Frans, A. (1970). Proceedings of Symposium 'Physiopathologie et clinique des affections respiratoires chroniques'. European Coal and Steel Community, Bull. physiopath. Resp., 6, 670-680.

Gough, J., James, W. R. L., and Wentworth, J. E. (1949). A comparison of the radiological and pathological changes in coalworkers' pneumoconiosis. J. Fac. Radiol. (Lond.), 1, 28-39.

International Labour Office (1959). Occup. Safety Hlth, 9, No. 2 , p. 63

Kremer, R. (1970). Apport de l'Hémodynamique Pulmonaire à l'Etude de la Pneumoconiose des Houilleurs, edited by Institut d'Hvgiène des Mines Havermarkt, pp. 22-3500. Hasselt, Belgium.

Lee, J., and Read, J. (1967). Effect of oxygen breathing on distribution of pulmonary blood flow in chronic obstructive lung disease. Amer. Rev. resp. Dis., 96, 1173-1180.

Lyons, J. P. (1970). Personal communication. , Clarke, W. G., Hall, A. M., and Cotes, J. E. (1967). Transfer factor (diffusing capacity) for the lung in simple pneumoconiosis of coal workers. Brit. med.J., 4, 772-774.

Macklem, P. T., Thurlbeck, W. M., and Fraser, R. G. (1971). Chronic obstructive disease of small airways. Ann. intern. Med., 74, 167-177.

Medical Research Council (1965). Definition and classification of chronic bronchitis for clinical and epidemiological purposes. Lancet, 1, 775-779.

(1966). Questionary on Respiratory Symptoms and Instructions for its Use. Printed and distributed by W. J. Holman Ltd., Dawlish, Devon, England.

Raine, J. M., and Bishop, J. M. (1963). A-a difference in $\mathbf{O}_{2}$ tension and physiological dead space in normal man. J. appl. Physiol., 18, 284-288.

Reynolds, J. A. (1968). Recording gas meter for measuring pulmonary ventilation. J. Physiol. (Lond.), 194, 52P-54P.

Rossiter, C. E. (1970). Personal communication.

Ryder, R., Lyons, J. P., Campbell, H., and Gough, J. (1970). Emphysema in coalworkers' pneumoconiosis. Brit. med. $J ., 3,481-487$.

Scadding, J. G. (1966). Patterns of respiratory insufficiency. Lancet, 1, 701-705.

Wagner, J. C. (1971). Aetiological factors in complicated coalworkers pneumoconiosis. Proceedings of the International Conference on Coalworkers Pneumoconiosis. New York Academy of Sciences, New York, 13-18 September.

Worth, G., Muysers, K., and Siehoff, F. (1963). Les gradients d'oxygène et de gaz carbonique de fin d'expiration au cours des silicoses du type punctiforme. Poumon et Caur, 19, 1377-1384.

\section{Addendum}

The following papers were seen too late for mention in the manuscript :

Lapp, N. L., Seaton, A., Kaplan, K. C., Huusaker, M. R. and Morgan, W. K. C. (1971). Pulmonary hemodynamics in symptomatic coalminers. Amer. Rev. resp. Dis., 104, 418-426.

Seaton, A., Lapp, N. R., and Morgan, W. K. C. (1972) Relationship of pulmonary impairment in simple coalworkers pneumoconiosis to type of radiographic opacity. Brit. $J$. industr. Med., 29, 50-55.

Received for publication October 19, 1971. 